\title{
ABDALLAH HAMMADI EN ESPAÑA: POEMAS DE JUVENTUD
}

\author{
JuAn Martos Quesada \\ Universidad Complutense de Madrid
}

En la actualidad, el escritor y profesor argelino Abdallah Hammadi es un novelista y poeta internacionalmente reconocido y uno de los más famosos representantes de la poesía de expresión en lengua árabe de su país, tal y como lo demuestran los honores con los que ha sido recibido, precisamente en la primavera de este año de 2016, en el Salón del Libro de París, en donde se ha podido asistir, junto a otros poetas árabes de relevancia, a la lectura de parte de sus poemas más representativos.

Como él mismo ha reconocido en varias ocasiones, los años que pasó en España en su juventud, como becario del gobierno argelino y, posteriormente, del Instituto Hispano-Arabe de Cultura para la realización de su tesis doctoral, fueron muy importantes para la evolución de su poesía, al incorporar a su conocimiento y dominio de la poesía árabe clásica la influencia de poetas de lengua castellana como Antonio Machado, García Lorca, Vicente Aleixandre o Pablo Neruda.

Nacido en la ciudad argelina de Constantina en 1947, durante la ocupación francesa, el inicio de la guerra de Liberación obligó a su familia a marcharse a Túnez, al igual que otros compatriotas suyos, a causa de la represora política antiárabe que llevó a cabo la potencia colonizadora; en este país realiza sus estudios de Primaria, para volver a su ciudad natal en 1962, año de la independencia de Argelia, en donde continuará con sus estudios de Secundaria, inmerso el país en el proceso de arabización que los nuevos gobernantes ponen en funcionamiento en 
los años siguientes ${ }^{1}$. Tras la obtención de su licenciatura en Letras en la Universidad de Constantina, comienza a trabajar como profesor en la misma, aunque al siguiente año inicia su estancia en España, en donde viene en el año 1973 y en donde permanece hasta la lectura de su Tesis doctoral, en el año 1980, viviendo a caballo, principalmente, entre las ciudades de $\mathrm{Ma}-$ drid y Granada, ciudad en la que trabé amistad con el escritor.

Cuando llegó a España, ya era un joven poeta publicado en su país, pues sus versos habían visto la luz en periódicos, como al-Nașr de Constantina, o en revistas especializadas de la ciudad de Argel como al-Muŷābid o al-Ša'b al-taqāfì , e incluso contaba ya con un nutrido diván de poesía en lengua árabe, aún inédito en aquella época titulado Tornado del norte sobre el sur (A'âšir al-šamāl 'alà al-ŷanüb), tal y como se recoge en el artículo de S. Fanjul'2.

$\mathrm{Su}$ contacto y afición a la poesía árabe clásica fueron muy tempranos, casi desde su niñez, pues como él mismo nos relata en el Preámbulo de su tesis doctoral:

Casi diariamente, mi padre solía darme dos o tres versos que yo aprendía de memoria a cambio de algunos céntimos para caramelos; con este dulce método fui acumulando cada vez más versos y asociando sus rítmicos sonidos con algo delicioso. Pasaron los años y en mi mente fueron grabándose estrofas y "casidas" por centenares hasta llegar a la adolescencia ${ }^{3}$.

${ }^{1}$ Acerca de este tema, véase el interesante artículo de Montserrat Benítez Fernández, "Un repaso a la política lingüística del Norte de África desde la descolonización”, en Anaquel de Estudios Árabes, 2002, núm. XXIII, pp. 6981.

${ }^{2}$ Serafín Fanjul, "Un poeta argelino en España: 'Abdallah Hammadi”, en Almenara, 1975, núms. VII-VIII, pp. 313-324.

${ }^{3}$ Editada posteriormente por la Fundación Abdul Aziz Saud al-Babtain, que le concedió un premio: Abdallah Hammadi, La poesía en el reino nazarí 
A su llegada a España, a principios de los años setenta del pasado siglo, la literatura árabe contemporánea en general sufría en nuestro país de un casi absoluto desconocimiento, que a duras penas intentaban solucionar los esfuerzos traductores del Instituto Hispano-Árabe de Cultura ${ }^{4}$ y del Departamento de Estudios Árabes e Islámicos de la reciente Universidad Autónoma de Madrid, cuya revista Almenara fue clave en este empe$\tilde{n} o^{5}$. Y si este desconocimiento ocurría con autores de países como Marruecos, Egipto, Iraq o Siria, puede uno imaginarse el tremendo vacío que había en nuestros círculos intelectuales y académicos sobre la poesía actual argelina ${ }^{6}$, más aún si ésta era de expresión en lengua árabe, pues la llevada a cabo por autores argelinos en lengua francesa, por razones obvias, era no mucho pero más conocida en nuestro país ${ }^{7}$.

de Granada (1232-1492), Kuwait, Fundación Babtain, 2004.

${ }^{4}$ Sobre esta institución y su importancia en la divulgación de la literatura árabe contemporánea en España, véase la obra de Miguel Hernando de Larramendi, Irene González González y Bernabé López García (coords.), El Instituto Hispano-Arabe de Cultura. Orígenes y evolución de la diplomacia pública española hacia el mundo árabe, Madrid, AECID, 2015.

${ }^{5}$ Sobre este empeño, $c f$. la obra de Miguel Hernando de Lerramendi y Luis Miguel Pérez Cañada, La traducción de literatura árabe contemporánea antes y después de Naguib Mabfuz, Cuenca, Universidad de Castilla-La Mancha, 2000.

${ }^{6} \mathrm{El}$ artículo de Luis Miguel Pérez Cañada acerca del caso concreto de la literatura argelina es esclarecedor: "Panorámica de los estudios y traducciones de literatura argelina en español”, en G. Fernández Parrilla, L. M. Pérez Cañada y R. Montoro Carrillo, Panorámica de los estudios y traducciones de la literatura del Magreb en español, Toledo, Escuela de Traductores de Toledo, 1998, pp. 17-26; véase también Nafissa Mouffok, "La traducción y el hispanismo argelino. Situación y perspectivas”, en Index.Comunicación, 2014, vol. 4, núm. 2, pp. 49-59.

${ }^{7}$ Sobre la poesía argelina actual en árabe, véase el artículo del profesor de la Universidad de Alicante Isaac Donoso "Antologías de poesía argelina con- 
El inventario de las publicaciones en España de la obra poética de Abdallah Hammadi traducida al castellano de estos años de juventud podemos cifrarlo en cuatro manifestaciones, pues la elaboración de su tesis doctoral sobre poesía nazarí, a la que dedicaremos asimismo unas líneas, merece una mención aparte:

- Cinco poemas, traducidos por el arabista Serafín Fanjul y publicados en un artículo de la revista Almenara, con una nota preliminar del mismo (véase nota 2); los títulos de estos poemas son "A Machado", “¿Poema al burro?, publicado en árabe por el periódico al-Nașr de Constantina el año anterior, “¿No volverá Neruda?", "Poema”, y "Silencio hondo", sumando entre todos unos trescientos cincuenta versos.

- Al año siguiente, en 1976, el mismo autor, Serafín Fanjul, en la sección "Páginas de poesía” de la revista Almenara ${ }^{8}$, traduce algunos poemas de cinco autores árabes residentes en aquella época en Madrid: de los palestinos AbdelKarim al-Huli y Ramzi Darwisch, del egipcio Ahmad Abdel-Aziz, del libanés Simon el-Deiri y del argelino Abdallah Hammadi. Para nuestro autor, seleccionó un largo poema que, bajo el título "Don Quijote se pone en camino", dedicaba Abdallah Hammadi al poeta español Vicente Aleixandre.

- En julio del año 1979, aparece en Málaga, editado por el autor, un libro -inencontrable hoy en día - que bajo el título Entre sol y arena, recoge en unas sesenta páginas la traducción española de una selección de poesía de Abda-

temporánea en lengua árabe", en Revista Argelina, primavera-verano 2015, núm. 0, pp. 29-40.

8 "Jóvenes poetas árabes en Madrid", en Almenara, 1976, núm. IX, pp. 203-216. 
llah Hammadi, llevada a cabo por él mismo, en donde se agrupan algunos de los poemas ya editados en nuestro país, otros que vieron la luz en lengua árabe y otros inéditos. A este respecto, es pertinente recordar que este mismo año, un equipo de profesores del departamento de Español de la universidad argelina de Orán encabezados por el poeta y premio Adonais Emilio Sola ( Zoubeida Hagani, Mokhtar Abdelwaret y Mohamed Benmebkhout) publica también en Málaga, en la editorial Cuadernos de Afrobética, dirigida por el escritor Francisco López Barrios, la primera antología bilingüe (españolfrancés $)^{9}$ de la poesía argelina contemporánea de expresión francesa, bajo el título País de larga pena. Pequeña antología de la poesía argelina contemporánea (1950-1978), en la que se recogen poemas de escritores del país vecino de tres generaciones. En la nota de presentación de este libro en el boletín Arabismo, se hace mención a una futura continuación, con la publicación de otra antología bilingüe (árabe-español) de poetas argelinos de expresión árabe a cargo del profesor Marcelino Villegas, continuación que, lamentablemente, nunca vio la luz y en la que, con toda probabilidad, hubiera estado presente Abdallah Hammadi.

- Por último, el profesor y arabista Pedro Martínez Montávez, en el año 1994, en un número monográfico sobre la producción poética árabe actual de la revista Arrecife de Murcia ${ }^{10}$, titulado Tiempo de poesía árabe, traduce un breve

${ }^{9}$ Véase el boletín informativo del Instituto Hispano-Árabe de Cultura Arabismo, enero-marzo 1980, núm. XXVII, que recoge la noticia en su página 7; véase también Isaac Donoso, op. cit., p. 16.

${ }^{10}$ Pedro Martínez Montávez, “Tiempo de poesía árabe”, en Arrecife, XXXIII-XXXIV (1994). 
poema de nueve versos de Abdallah Hammadi bajo el título "La palabra avergonzada", escrito durante su estancia en España.

La lectura y análisis de estos poemas tempranos de juventud nos hace llegar a una serie de conclusiones acerca de las principales características de esta primera poética de Abdallah Hammadi.

En primer lugar, es obligado y primordial destacar que la característica fundamental, y de algún modo esencial y que recorre transversalmente toda la actividad del poeta, es su indudable conocimiento y dominio de la poesía clásica árabe, de sus reglas y de sus principales rasgos; es, sin duda, el entramado, la base y los cimientos de toda su producción poética, que penetra en todos sus poemas y se muestra de manera orgullosa en todos sus versos, sea cual sea la forma o el tema elegido. Y este dominio de la estructura de la poesía clásica árabe no sólo le viene por el estudio de la misma y el conocimiento exhaustivo de sus principales autores, fruto de una formación literaria tradicional, sino también $-\mathrm{y}$, desde mi personal punto de vista - por la memorización de centenares de poemas clásicos que ha hecho que el ritmo y la métrica tradicionales árabes se hayan instalado de forma permanente en su mente y su expresión se haga como una cosa natural.

En segundo lugar, su estilo es, como afirma Serafín Fanjul, fruto de un esfuerzo personal e individual, que intenta esquivar su encasillamiento en una determinada escuela o tendencia, lo que le lleva a trabajar concienzudamente la elaboración de un poema, en un estilo un tanto rebuscado y enrevesado, con un uso prolijo de figuras literarias, retóricas y poéticas, más en el camino de una concepción clásica de la poesía que de una orientación más moderna y libre. Figuras como el hipérbaton, la 
alegoría, las comparaciones, las interrogaciones retóricas, las metáforas o las metonimias son habituales en sus creaciones.

En tercer lugar, es de destacar el enorme cuidado que tiene en la búsqueda del término exacto que exprese su sentimiento, lo que le hace trabajar un léxico rico y abundante, fruto también, cómo no, de su influencia de la poesía clásica árabe. La adjetivación en todos sus aspectos (epítetos, sinónimos, repeticiones, etc.) es un elemento visible en todos sus poemas, tanto en los escritos en lengua árabe como en la traducción de los mismos al español, lo que sin duda habrá supuesto un esfuerzo añadido a sus traductores.

En cuarto lugar, es necesario hablar de su temática, de sus temas favoritos, más inclinados a la reflexión y a la expresión de sentimientos humanos, como el amor, la soledad, el silencio, la contemplación o la reflexión íntima, que a temas de corte realista o de poesía social (sin que por ello, se niegue a tratar estos temas cuando es necesario hacerlo, en particular cuando la visión de esta realidad nos lleva al desaliento o a la desesperanza); no es, desde luego, un poeta al que se pueda clasificar de social y quizás por ello, Martínez Montávez no lo incluyó en su antología de la poesía árabe realista contemporánea ${ }^{11}$.

Por último, hemos reservado para el quinto lugar una característica sin duda fruto de su contacto con la lengua y la poesía en castellano, tanto española como hispanoamericana, como es la influencia de lo español y de los poetas de lengua castellana en su obra. Las influencias de Pablo Neruda, Antonio Machado, Vicente Aleixandre, Rafael Alberti, Federico García Lorca, Miguel Hernández o de los poetas andaluces de su tiempo, que tan bien conoció y leyó, son visibles en su quehacer poético, a lo que hay que añadir una sensibilidad especial por cantar temas de la cultura española, como Don Quijote o la Alhambra, o

${ }^{11}$ Pedro Martínez Montávez, Poetas realistas árabes, Madrid, Rialp, 1970. 
rendir homenaje a sus escritores favoritos dedicándole poemas muy personales, como los dedicados a Neruda o a Machado.

Como ya hemos dicho, creemos pertinente traer a colación el trabajo de investigación llevado a cabo en España, en estos años de juventud, por Abdallah Hammadi sobre la poesía nazarí y que fue fruto de su tesis doctoral, dada la importancia que tuvo para el conocimiento de la cultura del reino musulmán de Granada y, en particular, para el estudio de la literatura nazarí, campo no suficientemente analizado ni traducido en esa época ${ }^{12}$. La tesis doctoral, con el título La poesía en el Reino Nazari de Granada (1232-1492) y dirigida por la profesora M. J Jesús Rubiera Mata, fue leída el día 16 de junio de 1980 en el Departamento de Árabe e Islam de la Universidad Complutense de Madrid, siendo publicada posteriormente en Kuwait, en el año 2004, por la Fundación Abdul Aziz Saud al-Babtain.

Con un manejo exhaustivo de las fuentes conocidas y con el añadido de, al menos tres manuscritos nuevos sobre el tema descubiertos por el autor, la tesis se divide en diez capítulos, en donde se analiza la producción poética de los escritores granadinos de esta etapa final de al-Andalus, a través del estudio de los diversos temas presentes en sus poemas. En el capítulo I se trata el panegírico y las diferencias de éste con el oriental; el capítulo II está dedicado a la poesía como arma para llevar a cabo súplicas o controversias; en el III se nos habla de la sátira como tema poético, confrontando su escasez en Granada con la abundancia de este género en Oriente; el capítulo IV está dedicado al tema del amor y sus múltiples variantes; el capítulo $V$ trata del libertinaje (al-muŷūn), entendido como el canto a los placeres que nos ofrece la vida; el VI nos presenta la vida devota, la poesía religiosa, en sus manifestaciones mística, ascética o

${ }^{12}$ Para una panorámica de los estudios sobre este tema, véase Celia del Moral, "La literatura del periodo nazarí", en Concepción Castillo Castillo (ed.), Estudios nazaries, Granada, Universidad de Granada, 1997, pp. 29-72. 
sapiencial; el siguiente capítulo, el VII, está dedicado a los temas festivos, tanto religiosos como profanos; el capítulo VIII se refiere a los trenos, a los lamentos fúnebres, género poético en donde se analizan las diferentes modalidades existentes según la relevancia social del finado; el capítulo IX, quizás el más abigarrado de todos, contempla temáticas variadas como las correspondencias (al-ijwāniyāt), la patria o el paisaje; y, por último, en el capítulo X, Abdallah Hammadi reflexiona sobre las características de esta poesía nazarí, en particular su acusado conservadurismo. No cabe duda que este estudio y traducción de los poetas nazaríes de al-Andalus a través de su temática ha marcado un hito en el conocimiento de este capítulo de la poesía clásica árabe de occidente.

$\mathrm{Y}$, finalmente, como complemento a estos apuntes sobre la poesía de juventud de Abdallah Hammadi, creemos oportuno hacer mención, aunque sea de forma breve, a su actividad como traductor y estudioso de la literatura española e hispanoamericana. Como hispanista reconocido en el mundo árabe, nuestro autor ha llevado a cabo, desde mediados de los años setenta del pasado siglo, un buen número de traducciones al árabe y de estudios de la poesía en lengua castellana. Labor nada fácil y que necesita la sensibilidad de un poeta para acometerla, además de un excelente conocimiento de las dos lenguas, árabe y español. Las reflexiones a las que le ha llevado esta experiencia traductoria las ha expresado de forma precisa y sincera Abdallah Hammadi en una intervención durante las Jornadas de Hispanismo Árabe que tuvieron lugar en Madrid a finales de mayo de $1988 .^{13}$

${ }^{13}$ Abdallah Hammadi, "La traducción literaria a través de mi modesta experiencia” (en lengua árabe), en Fernando de Ágreda Burillo (ed.), La traducción y la crítica literaria. Actas de las Jornadas de Hispanismo Arabe. Madrid, 24-27 de mayo de 1988, Madrid, Agencia Española de Cooperación Internacional (AECID), 1990, pp. 465-470. 
Su actividad y su afán por dar a conocer la literatura en lengua española al mundo árabe a través de su traducción la comenzó en la revista iraquí al-Aqlām, en donde, a lo largo de los años 1975 y 1976 tradujo poemas de Vicente Aleixandre y Pablo Neruda ${ }^{14}$. Esta labor de traducción y publicación en revistas y periódicos le ha acompañado a lo largo de su vida aunque, por citar algunas de sus obras más importantes, destacaremos dos libros que estimamos relevantes en este campo de su actividad académica por la fama que llegaron a alcanzar en Argelia. Nos referimos a la introducción que hizo para el estudio y conocimiento de la poesía española contemporánea, con una amplia antología de la misma, publicada en su país a mediados de los años ochenta ${ }^{15}$ y a la selección de poetas y poesía andaluza contemporánea que llevó a cabo a principios de este siglo, fruto de sus contactos y conversaciones con escritores de esta tierra española respecto a la influencia de la presencia árabe en España ${ }^{16}$.

Finalmente, de entre su nutrida labor como hispanista, traeremos a colación también dos de sus obras - aparte de la ya mencionada introducción a la poesía actual española-, las dedicadas al estudio y análisis de la obra de dos grandes autores sudamericanos, Pablo Neruda y Gabriel García Márquez dadas a conocer en los años ochenta y publicadas respectivamente en Túnez y Argelia ${ }^{17}$.

${ }^{14}$ Abdallah Hammadi, "Diez poemas de Vicente Aleixandre" (en lengua árabe), en al-Aqlām, Iraq, 1975, vol. 2, pp. 13-17; "Poemas de Pablo Neruda" (en lengua árabe), en al-Aqlām, Iraq, 1976, vol. 10, pp. 21-28.

15 Abdallah Hammadi, Introducción a la poesía española contemporánea (en lengua árabe), Argel, ENAL, 1985, 320 páginas.

${ }^{16}$ Abdallah Hammadi, Al-Andalus, entre el sueño y la realidad (conversaciones con poetas andaluces) (en lengua árabe), Constantina, Universidad de Constantina, 2004.

17 Abdallah Hammadi, Aproximación al poeta Pablo Neruda (en lengua árabe), Túnez-Argel, coeditado por la SNED de Argelia y la MTED de Túnez, 1985; Gabriel García Márquez: pionero del realismo mágico (en lengua 


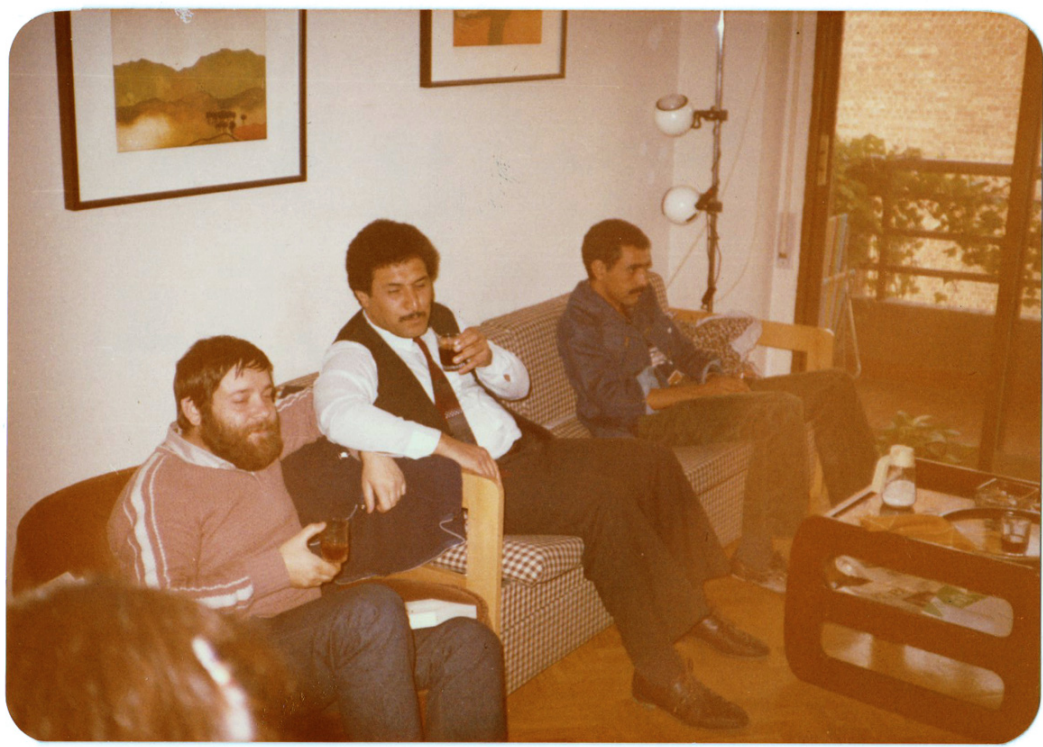

Abdallah Hammadi, su hermano y el autor de este texto en su casa de Madrid

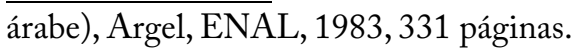

